\title{
Physical model of kimberlite pipes formation: new constraints from theory of non-homogenous physical vacuum
}

\author{
Dmitriev, A.N. ${ }^{1}$, Dyatlov, V.L. ${ }^{2}$, and Litasov, K.D. ${ }^{1}$ \\ 1. Institute of Geology SB RAS. 630090 Norosibirsk. Russia \\ 2. Institute of Mathematics SB RAS 630090 Norosibirsk. Russia \\ E-mail: dmizola uiggm.nsc.ru. kostik âuiggm.nsc.ru
}

The classic models of kimberlite eruption include explosive-boring volcanism, fluidization, and hydrovolcanism briefly reviewed in (Mitchell, 1986). All the models have both positive and negative features. Source of explosion energy is one ot the most important problem discussed.

We present here new constraints to physical model of kimberlite formation based on a theory of physical vacuum. The kimberlite pipes are considered as a intrusion of vacuum domain (VD) into the lithosphere. The problems of intrusion, movement and explosion of VD in the Earth crust are solved using a model of non-homogenous physical vacuum (NPV) (Dmitriev, Dyatlov, 1996). NPV as a localized space volume, is described via a model of macroscopic electrogravidynamics (Dyatlov, 1995).

The explosion model considers quasi-statical case and establishes deep-seated field interaction between VD and solid rocks, which takes into account a partial time derivative. Well known electric and magnetic field equations in quasi-static approximation, where time delay caused by electric wave propagation is equal to 0 , are also used.

Macroscopic electrogravidymamics deal not only with an electric waves length but also with a length of gravispin waves. Studied in this model portion of space includes VD body and its nearest neighbourhood.

In quasi-static approximation (Dmitriev, Dyatlov, 1998), the problems of electric field and electric current and problems of magnetic field and electric current are divided. Besides, problems of electric gravitation and problems of magnetospinorics are also separated. Main problems of deepseated explosion of VD are solved using our methodologies and groups of equations in electric gravitation and magnetospinorics. General postulates of VD theory may be considered as following:

1. An existence of VD is proved by numerous records of natural self-luminous bodies in the atmosphere and near-the-Earth space. Spherical bodies vary from $\mathrm{cm}$ (for example fireball) to $\mathrm{km}$ order (Dmitriev et al., 1992). There are dozens of descriptions of VD explosion in the atmosphere with energy emission up to several megatons (trinitrotoluene equivalent).

2. As VD can easily penetrate into solid space, an estimation of the attraction force of VD to the Earth is considered (Dmitriev, Dyatlov, 1998). It is found that this force is proportional to VD radius cubed $\left(R^{3}\right)$. Therefore, bigger $V D$, faster it attracts to the Earth and intrusion to the lithosphere. Field mapping of VD occurrence as self-luminous bodies allowed conclusion that VD were found within areas having specific geophysical features. Presence of active faults, large regional or local high-gradient and sign-reversed magnetic anomalies, anomalous electric conduction, and deep-seated electric generation are necessary. We have to emphasize that Yakutian kimberlite province satisfies all these conditions.

3. The problem of VD intrusion into conductive matter and the equations for current density in electric conductive matter were prodused (Dmitriev, Dyatlov, 1998). It was shown, that VD can turn to electric and gravitational dipole in air at low density of matter. If the air density is not equal to $0 \mathrm{VD}$ transforms to coupled electric mono-charge:

$$
\mathrm{q}=\left[-\mathrm{a}_{\varepsilon} / \eta_{\mathrm{o}}\right] \times\left[\rho_{\mathrm{G}} \mathrm{V}\right]
$$


where $V$ is VD volume, $a_{\varepsilon}$ is electrogravitational coupling constant $\left(a_{\varepsilon} \sim 1\right), \eta_{0}=1.161 \mathrm{~kg} / \mathrm{K}, \rho^{\prime}=-a_{\varepsilon} \eta_{0} \cdot$ ${ }^{1} \rho_{G}$ is density of coupled polarization electric charge, $\rho_{G^{-}}$air density $\left(1293 \mathrm{~kg} / \mathrm{M}^{3}\right)$. The electric field on VD surface is described by equation:

$$
E=\rho^{\prime} \times\left[R /\left(3 \varepsilon_{0}\right)\right],
$$

where $\mathrm{R}$ is a radius of VD sphere, $\varepsilon_{0}=8.85 \times 10^{-12} \mathrm{~F} / \mathrm{m}$. $E=-4,18--4,18 \times 10^{3} \mathrm{~V} / \mathrm{m}$, if $\mathrm{R}=1-1000 \mathrm{~m}$, and $a_{\varepsilon}=1$. Thus, VD in the atmosphere has weak electric mono-charge and insufficient electric field, which is not enough to produce electric sparkover of air, and accompanied depolarization is practically negligible. It explains durable existence of VD in the atmosphere.

4. VD depolarization in the lithosphere (first $10-15 \mathrm{~km}$ ) speeds up steeply due to changes in density and physical state of matter. According to (1), electric mono-charge rises in factor of 3-4 comparing with its magnitude in air, if $\rho_{\mathrm{G}}=10^{3}-10^{4} \mathrm{Kr} / \mathrm{m}^{3}$. VD depolarization in the lithosphere is accounted for by electric conduction current.

The density of heat power are connected with density of conductive current within and outside of VD as:

$$
\mathrm{P}_{\mathrm{T}}=\sqrt{\mathrm{E}}=J_{r}^{2} / \sigma,
$$

where $\sigma$ is specific resistance. Extracted heat power within VD is

$$
\mathrm{P}_{\mathrm{Ti}}=\left[4 \pi \rho^{\prime 2}\right] /\left[9 \times 5 \sigma \mathrm{T}^{2}\right] \times \mathrm{e}^{(-2 \mathrm{t} T)} \mathrm{R}^{5},
$$

extracted heat power outside of VD (in nearest neighbourhood) is

$$
\mathrm{P}_{\mathrm{Te}}=\left[4 \pi \rho^{\prime 2}\right] /\left[9 \sigma \mathrm{T}^{2}\right] \times \mathrm{e}^{(-2 \mathrm{t} \mathrm{T})} \mathrm{R}^{5},
$$

combined heat power is

$$
\mathrm{P}_{\mathrm{T}}=\mathrm{P}_{\mathrm{Ti}_{\mathrm{i}}}+\mathrm{P}_{\mathrm{Te}}=\left[2 \times 4 \pi \rho^{\prime 2}\right] /\left[3 \times 5 \sigma \mathrm{T}^{2}\right] \times \mathrm{e}^{(-2 \mathrm{TT})} \mathrm{R}^{5},
$$

Energy of VD contact with electric conductive rock derived from equations (4-6) is

$$
\mathrm{W}_{\mathrm{T}}={ }_{0}{ }^{\alpha} \mathrm{P}_{\mathrm{T}} \mathrm{dt}=\left[\rho^{\prime 2} \mathrm{R}^{2}\right] /\left[5 \varepsilon \varepsilon_{0}\{1-\mathrm{a} \varepsilon 2 / \varepsilon\}\right] \times \mathrm{V},
$$

where $V=4 \pi R^{3} / 3$ is a volume of VD sphere, $\varepsilon$ has complex physical means but its most simple explanation is a electrogravitational coupling parameter. $\varepsilon>0$ for positive $V D, \varepsilon<0$ for negative $V D$

Using Maxwell equations for rate of relaxation, a depolarization in geological-geophysics media occurs in regime of explosive energy emission $W_{T}$, i.e. "contact" explosion takes place. This explosion has energy density described as

$$
\mathrm{W}_{\mathrm{T}}=\mathrm{W}_{\mathrm{T}} / \mathrm{V}=\left[\rho^{\prime 2} \mathrm{R}^{2}\right] /\left[5 \varepsilon \varepsilon_{0}\left\{1-\mathrm{a}_{\varepsilon}{ }^{2} / \varepsilon\right\}\right] .
$$

From (8) the explosion energy is proportional to radius of VD sphere and has magnitude near $10^{6} \mathrm{~J} / \mathrm{m}^{3}$, if $\mathrm{R}=1 \mathrm{~km}$. During a field trip to Altay mountains, one of the authors observed the $\mathrm{VD}$ 
sphere $8 \mathrm{~km}$ in diameter (Dmitriev et al., 1992). Hence, if such a sphere would produce "contact» explosion in shallow lithosphere, the energy emission would be expected near $8 \times 10^{15} \mathrm{~J}$.

5. Specifics of «contact» explosion, where an explosive has field nature and is found within crystal structure of rocks, must be taken into account. This is specific micro-explosive with snapaction pulse heat production and electromagnetic radiation (characteric time is $10^{-8} \mathrm{c}$ ). It does not shift a matter but transforms it within explosion conduit in situ due to physical-chemical state of matter and in heat and high-power vortixes. We emphasize self-localized nature of "contact» explosion that produce minimal changes in neighbouring rocks. If we consider positive and negative VD varieties, we can expect abundant diversities of «contact» explosion actions both in kinematic features, and in physical-chemical transformations. Another specific features of «contact» explosion is its multistage development, which is determined by VD transportation where movement is developed in magnetic and spin field. Explosion condition is depended on VD depolarization intensity changes. During depolarization main explosion force is produced by gravitation field. Explosion and its sequences have well-defined space localization.

The mathematical model of NPV is a new direction in physics (Dmitriev, Dyatlov, 1998). Their «contact» explosion equations have to play an important role in geological processes. The effect of "contact» explosion in the lithosphere can explain such phenomena as a coexistence of high grade and low grade metamorphic rocks with sharp contact in the Earth crust, or some surface processes

We suppose that «contact» explosion theory may be applied to explain the formation of kimberlite pipes. VD very sensitive to activity of faults of ancient dikes. Reactivation of deep faults during kimberlite intrusion from the depth cause VD intrusion from above. Thus, VD explosion in shallow lithosphere can accompanies kimberlite eruptions and would be important source of explosion energy, due to colossal power effect with inexpected action. Moreover, VD can originate and exist not only in the atmosphere and nearest space, but also in the lithosphere or in the mantle.

\section{Reference}

Dmitriev, A.N., Poholkov, Yu.P., Protasievitch, E.T., and Skavinskii, V.P., 1992, Plasma generation in energy active zone: United Inst. of Geology, Geophysics, and Mineralogy SB RAS Publ., 212p. (In Russian).

Dmitriev, A.N., and Dyatlov, V.L., 1996, A model of non-homogeneous physical vacuum and natural selfluminous formations: IICA Transact., Novosibirsk, v.3, p.65-76 (In Russian).

Dmitriev, A.N., and Dyatlov, V.L., 1998, Planetophysical function of non-homogeneous physical vacuum: Inst. of Mathematics SB RAS Publ., , 377p. (prep., in Russian with English abstract).

Dyatlov, V.L., 1995, Linear equation of macroscopic electrogravidynamics: NSA, MITPF, preprint №11, Moscow, 24p. (In Russian).

Mitchell R.H. Kimberlites: mineralogy, geochemistry, and petrology: Plenum Press, NW, 1986, 442p. 